\title{
Application of Project Teaching Method on Statistical Analysis Teaching
}

\author{
Yuan Zhang \\ Shandong Medical College, Jinan, Shandong, 250014
}

Keywords: Project Teaching Method, Statistical Analysis, Teaching Progress

\begin{abstract}
Applied Statistics is one of the core courses in economics and management major. This article summarizes the teaching experience and teaching reform practice, combined with the project teaching method, takes the marketing major as an example to discuss how to organize applied statistics teaching for different professions.
\end{abstract}

\section{Introduction}

Applied Statistics is one of the core basic courses of economics and management major, which enables students to correctly interpret and use common statistical indicators and improve students' ability to collect and process statistical data through statistical basic theories and methods. Statistics can be applied Methods to solve the practical problems in economic management. How to cultivate students' comprehensive abilities of collecting, sorting, analyzing and solving practical problems by using the theory and practice of statistics to study the data of socio-economic management by using the principles and methods of statistics is a problem which teachers have been exploring all along.

\section{Project Teaching Method Characteristics}

Under the guidance of the teacher, a relatively independent project is handled by the students themselves, including the collection of information, the design of the project, the implementation of the project and the final evaluation. This is the project pedagogy. Through the project implementation process, students can understand and grasp the basic requirements of the whole process and each link and acquire the necessary professional skills. The introduction of the project teaching method in the teaching of applied statistics in higher vocational education is conducive to introducing the actual statistical work process into the classroom. At the same time, it deepens students' knowledge and enhances the attractiveness of the classroom. Moreover, the project teaching method can design different work items according to the practical application of applied statistics in different majors so that students can combine their own specialties while applying applied statistics to improve the ability of analyzing and solving problems.

\section{Project Teaching Method in the Teaching of Statistics Significance}

The project teaching method is based on the students' autonomy and exploratory learning, and adopts a method similar to scientific research and practice to promote the active and active development of students. In the teaching activities, teachers will need to solve the problems or tasks to be completed in the form of a project to students to complete independently, from the collection of information, the design and implementation of the program, to complete the task after the evaluation, by students involved. The role of teachers in the teaching of project pedagogy is to consult, guide and answer difficult questions. Through fieldwork on a project-by-project basis, all students are able to understand and grasp the basic requirements of every aspect of completing a project and the key and difficult points of the whole process. Students in the project practice, understanding and grasp of the curriculum requirements of knowledge and skills, to experience the hardships and fun of innovation, training to analyze and solve problems and team spirit and cooperation ability. Statistics is a methodology science, is a methodological discipline with a wide range of applications and strong practicability. How to apply its theories and methods scientifically 
and accurately to the practical work of all walks of life is an important topic in the practice of statistics. The most prominent feature of the project pedagogy is "learning by doing", which is in line with the inquiry-based teaching mode and is applicable to cultivating students' ability to independently analyze and solve problems. More importantly, in the process of learning professional knowledge and practicing professional skills, we have learned the methods and qualities of lifelong learning. We have cultivated professional ethics and professional accomplishments and created innovative, entrepreneurial and vocational skills. The project pedagogy conforms to the level and practicality of the content of financial professional courses. Students can learn the theoretical and methodological skills of statistics step by step in accordance with the learning path from the table to the layer by layer, so that students can continuously attain the sense of accomplishment. The earth stimulates the desire for knowledge, so as to cultivate the self-learning ability of independent exploration and courage to forge ahead.

\section{Project Teaching Method in the Implementation of Statistics Teaching}

Carefully designed and proposed project tasks. Careful design of the project tasks is a prerequisite for carrying out the project teaching method. The quality of the project tasks directly affects the teaching effectiveness. Therefore, the design and layout of the project are crucial. Project tasks should focus on teaching syllabus, teaching materials in close conjunction with each chapter content, and according to the characteristics of students, the school's teaching resources, well-designed training objectives. Project tasks should be operable, close to the actual student life, focusing on professional ability training and other characteristics. For example, prior to studying "Correlation and Causality Analysis," teachers first designed a project task for students to think about their level of education and unemployment. During the economic crisis (1929-1933), well-educated people tended to be unemployed for a short time . Can education save you from unemployment? Because this project is very close to the reality of life, students are very interested, will choose to study the statistical methods to collect data for thought analysis. Teachers promptly lead the teaching content in this section --- Correlation and causation analysis, informing students that whether there is a correlation between education and unemployment can be calculated by calculating the correlation coefficient, but the correlation is not equal to causation. And then pointed out that the current project pending us to learn the relevant knowledge before we can solve, so that students with problems and tasks to learn, thereby enhancing classroom efficiency.

Timely guide and analyze the project elements. Each project contains new and old knowledge. After students accept the project, they first think about how to complete the project and what problems they can not solve in completing the project. These are the points they want to know. Teachers timely imparting new knowledge to them, to mobilize the initiative of students seeking knowledge. For example, when it comes to "controlling the average number of confounding factors," the teacher devised a project: "Is there a gender bias in graduate enrollment?" After accepting the project tasks, students are asked to discuss what types of typical majors to choose from among the graduate programs, what data collection and consolidation methods are used, and what statistical methods are used to analyze them. Teachers should promptly guide the students' possible problems and seek ways to solve the problems by using the old and new knowledge in the textbooks to help students to meet the problems they may encounter in completing the project. For example, students in the project research and analysis, will encounter the impact of professional choices and gender-induced mixed together, making the enrollment rate of men and women is not much difference between. Teachers should make use of the new knowledge in the textbook to control the confounding factors such as the choice of profession so as to guide the students to seek solutions to the problem. That is to say that it is only reasonable to compare the weighted average of the structurally similar subgroups, respectively, and the ordinary average does not work because it ignores the difference in size between the lines. The result is that the weighted average enrollment rate of boys is less than the weighted average enrollment rate of girls. This is because the weighted average controls the confounding factor --- professional choice. Students through this project learned new knowledge to solve practical problems, but also accumulated some practical experience 
and cultivate students' practical ability.

Interact and cooperate to complete the project plan. Implementation of project planning, project implementation, is an important part of the project teaching method. Under the influence of constructivism learning theory, the project pedagogy creates "scenarios" by selecting "project items", learning through "collaborative learning" and accomplishing "meaning construction" through completion of "project items". In order to realize the teaching goal of this pedagogic method and accomplish the construction of "meaning", it is necessary to pass the students' project practice activities. During the activity, students should be able to "migrate" new and old knowledge, sense and rational knowledge, and students should have occupation Ability, entrepreneurial ability, ability to innovate to be trained. "Collaborative Learning" is the key to "meaning construction." Therefore, we should attach importance to interactive cooperation in carrying out the project, which includes "teacher-student cooperation" and "living-body collaboration". The activities should be carried out in small groups. In order to carry out the activities smoothly and effectively, it is very important to conduct reasonable staffing, Grouped based on the general: the student's academic performance, knowledge structure, learning ability, personality traits, such as men and women, mainly in the form of complementarity, with good grades and poor performance with introverted and introverted With the other. The group of students to 5 to 8 people as a group, each group set up a "project manager", fully responsible for the group's discussion and implementation of the project to discuss the implementation of the project team to adopt collaborative approach to learning, under the command of the project manager, Division of labor for each member. For example: the design ability of the overall project responsible for the planning, exporting, lively students can conduct information surveys, data collection, computer operations ability to complete the reporting courseware design, good results can be analyzed and forecast data And so on, members of the hard work of the results and all members to share.

\section{Head Teaching Method of Teaching Effectiveness}

Students interest in learning in the classroom. Interest is the driving force of learning. The project teaching method takes the project task as the leading factor. The project is designed by the teachers or the students themselves. Close to life, practicality, the students' thinking is easily awakened. Through the cooperation and interaction, the project tasks are easy to produce a sense of success, learning autonomy and Initiative to give full play. At the same time, the project teaching method attaches importance to the process of activities, practice and theory are highly integrated, teachers in the activities play a leading and supporting role, so that students from the pure theory of passive teaching to liberate.

Students' comprehensive ability is cultivated. The realization of a project outcome in the project pedagogy is not only the mastery of one or a few theoretical knowledge points of the students, but also the development of various thinking qualities, practical ability, professional ability, entrepreneurial ability, Innovation and comprehensive ability such as training and training.

Student's academic performance to maintain good posture. Before the students of professional learning is generally passed through the exam rote to meet the exam, "remember fast, forget too fast," through the project teaching students practice and understanding based on the more easily grasp the knowledge and can form Long-term memory, the basic knowledge has become solid.

Teachers' own qualities are developed. Through the practice and research of the project teaching method, it has greatly promoted the teaching and research level of teachers. Past teachers with a book, a teaching staff to change the status of the classroom, teaching preparation has become the primary task of teaching design, while the overall quality of teachers has also been the corresponding development.

\section{Conclusion}

Any kind of teaching method is not a panacea, the project teaching method is also true, it should be based on the students of different ages, different academic foundation, different qualities to 
design, should also be based on the specific content of the textbook in a timely manner, but also with other teaching The combination of means, such as "enlightenment teaching method" and "case teaching method" are all very suitable for the teaching of specialized courses. Only when a variety of teaching methods are used interchangeably can classroom teaching be richly endowed, students 'interest in learning lasts long, teachers' Smoothly completed.

\section{References}

[1] Tao Ye. One-dimensional Linear Regression Analysis Teaching Improvement Strategy [J] .New Rural Science and Technology. 2017 (10)

[2] Yang Chunhua, Li Xiang. Application of Statistics in Production Practice [J] .Science and Technology Innovation Guide. 2017 (21)

[3] Wang Yu. The Practice of Applied Statistics Teaching Reform Based on the Causes of Learning Difficulty - A Case Study of East China University of Science and Technology [J]. Acta Physica Sinica. 2017 (07)

[4] Zhang Yuanyuan, Yuan Fenqiang, Chen Libu. "Internet + homework" mode in applied statistics teaching $[\mathrm{J}]$. Industry and Technology Forum.

[5] Renzhong. Study on Teaching Reform of Applied Statistics under the Network Environment [J] .News Economy Information. 2017 (08)

[6] Yang Jinying, Wan Aying. Hulunbeier college applied statistics professional transformation development strategy [J]. Hulunbeier College Journal. 2017 (01)

[7] Zhang Zheng. Application Statistics and Application in Big Data Background [J]. Shanxi Youth. 2017 (01) 